\title{
RESEARCH OF THE TEMPERATURE INFLUENCE ON THE CHANGE OF TITANIUM ALLOY MECHANICAL PROPERTIES BY MEANS OF THE OPTICAL CONTACT-LESS ANALYSIS
}

\author{
David KOREČEK, Pavel SOLFRONK, Jiří SOBOTKA \\ TUL - Technical University of Liberec, Liberec, Czech Republic, EU, \\ david.korecek@tul.cz
}

https://doi.org/10.37904/metal.2019.826

\begin{abstract}
Today, more and more accent is in the automotive, aerospace and energy industries put on the use of materials with the specific utilize properties such as high strength and at the same time sufficient ductility to enable the production of given part. In addition to these key forming features, low weight and, last but not least, good corrosion resistance are also important. In view of the above requirements, titanium alloys appear to be a progressive construction material for the most demanding applications in a wide range of engineering production. This paper deals with the change of mechanical properties of titanium alloy with the trade name Grade 5 (Ti-CP $6 \mathrm{Al}-4 \mathrm{~V}$ ). The change of mechanical properties is evaluated by means of a static tensile test carried out in an insulated temperature chamber with resistance heating. The tests are carried out in the selected temperature interval, which should sufficiently represent changes in mechanical properties depending on temperature. Scanning and evaluation of the test deformation characteristics is performed by using an advanced contact-less optical deformation analysis method, which operates on the principles of the photogrammetry. Lab NET software and Mercury software are used for this purpose. The results of the measurements are dependencies of the titanium alloy mechanical properties on temperature within the selected temperature interval. Furthermore, the resulting temperature dependence of mechanical properties can be used as input material characteristics into the numerical simulation environment of the material forming process.
\end{abstract}

Keywords: Mechanical properties, metal forming, titanium alloy grade 5, temperature, photogrammetry, numerical simulations

\section{INTRODUCTION}

Titanium and titanium-based alloys have been known since the 18th century, when they were discovered by W. Gregor and M. K. Klaproth, but in industrial production, titanium and its alloys were not used until World War II, where they were mainly used in manufacturing military equipment and aviation. In addition, titanium is nowadays used in the chemical and mechanical industries [1].

Today, light alloy materials are a highly demand and attractive materials to be used in variety of engineering industries, while maintaining high strength, ductility and corrosion resistance requirements. Research institutes all around the world are engaged in the issue of achieving the optimum properties of the resulting component that will respect the above aspects. Titanium alloys, in view of these properties, appear to be a useful construction material for the production of components applied in various sectors of the automotive, aerospace and energy industries. Compared to steel, titanium has almost half the density (thus weight), while maintaining a similar, if not higher, strength than that made of steel. However, the lack of experience in its processing and the relatively high cost limits the wide utilization of titanium and its alloys in the mechanical engineering [2,3].

This paper is devoted to research the mechanical properties of titanium alloy Ti-CP 6Al-4V, which can be used for forming and it can be apply in technical practice. The research is devoted to testing mechanical properties in dependence on the material forming temperature. To determine the mechanical properties, this alloy is tested by using a static tensile test at selected testing temperatures (from RT to $900{ }^{\circ} \mathrm{C}$ ). 


\section{EXPERIMENTAL PART}

The experimental part of this article was aimed at determining changes in mechanical properties of titanium alloy $6 \mathrm{Al}-4 \mathrm{~V}$ due to the specified elevated temperatures during material testing. A temperature range from RT to $900^{\circ} \mathrm{C}$ was chosen, namely RT, $100,300,500,700$ and $900{ }^{\circ} \mathrm{C}$. The material was tested using the static tensile test and non-contact optical extensometer. The static tensile test was performed to determine the basic mechanical properties of the tested material such as proof yield strength $R_{\mathrm{p} 0,2}$, ultimate tensile strength $R_{\mathrm{m}}$, total ductility $A$ and uniform ductility $A_{g}[4,5]$.

\subsection{Static tensile test}

Because of titanium oxidation under elevated temperatures, there was necessary to carry out static tensile test in the vacuum. For this purpose, the modern thermal-mechanical simulator Gleeble 3500 (Figure 1) was used, where it is possible to realize the loading of the material in an insulated vacuum chamber and in addition it is possible to apply heat load on the sample.

Circular test rods with an initial diameter of $D_{0}=8 \mathrm{~mm}$ and an initial length of $L_{0}=40 \mathrm{~mm}$ were mechanically clamped and tested in the jaws of the Gleeble test machine. The force record of the test was taken by a force load sensor that is integrated in machine. Specimen deformation was scanned by using an optical contactless system from Sobriety Ltd., which was used to optically scan the specimen linear extension during the test until specimen failure. In order to carry out the test, it was necessary to provide the sample with condenserdischarged welded thermocouples for temperature scanning during the test. Moreover, on the specimen's surface was needed to apply contrast pattern to detect and evaluate the deformation $[4,5]$.

The tests were conducted at a selected temperature range from RT to $900{ }^{\circ} \mathrm{C}$ with a standard loading rate of $10 \mathrm{~mm} / \mathrm{min}$. Channel of extension was performed by using software Mercury, which processes frames from the camera. FPS (frames-per-second) for these tests was 5 frames per second. Finally, the whole test (force and extension channel) was evaluated by means of software OriginPro 9.
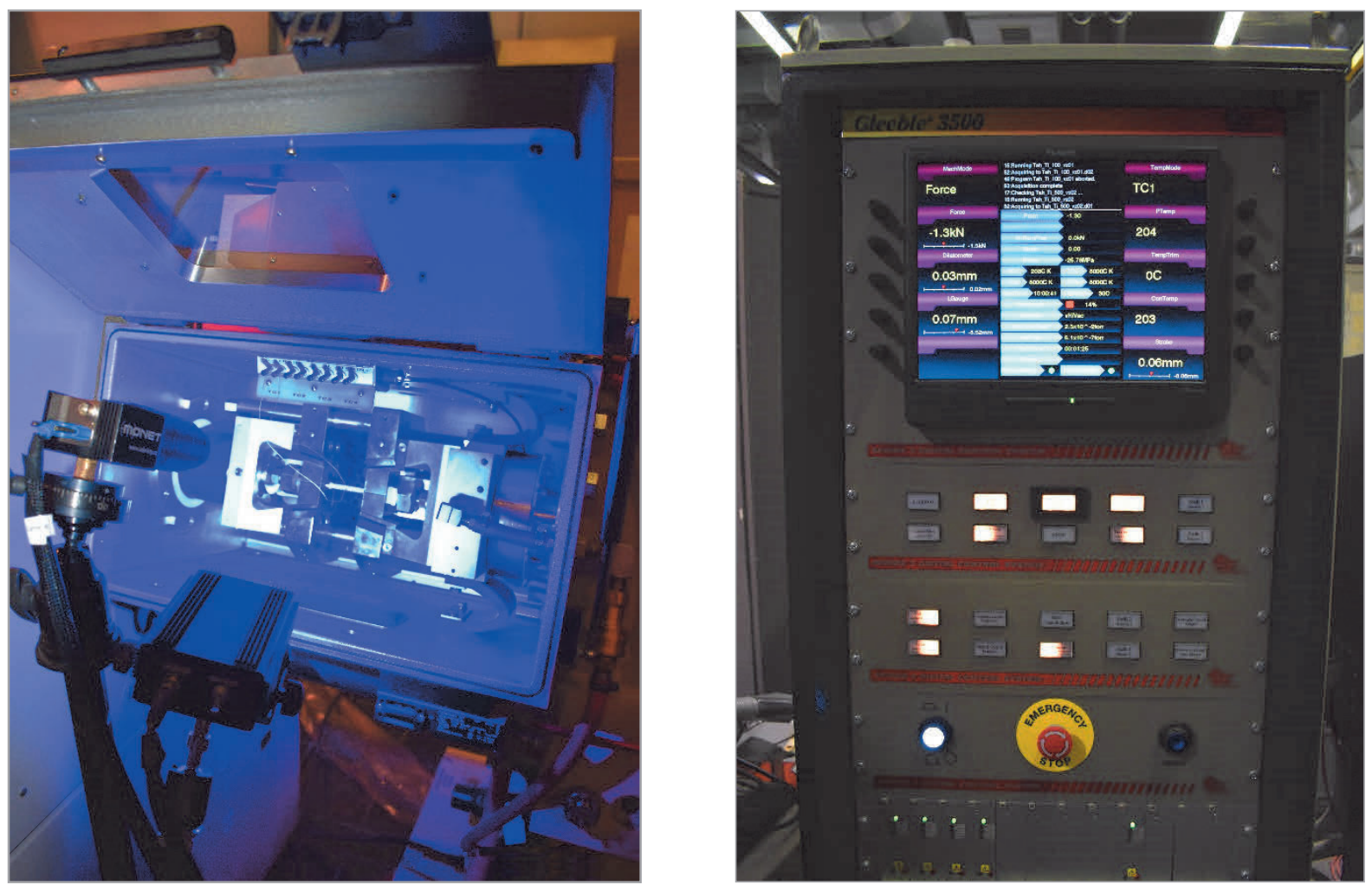

Figure 1 Realization of the test by Gleeble Machine and optical system (mono-camera and lightning) 
In Figure $\mathbf{2}$ can be seen monitoring of test by the Mercury software as well as the comparison of test specimens after static tensile test at selected temperatures, upward RT, 100, 300, 500,700 and $900{ }^{\circ} \mathrm{C}$. It is possible to observe an deformation increase in the neck region due to the elevated temperatures.
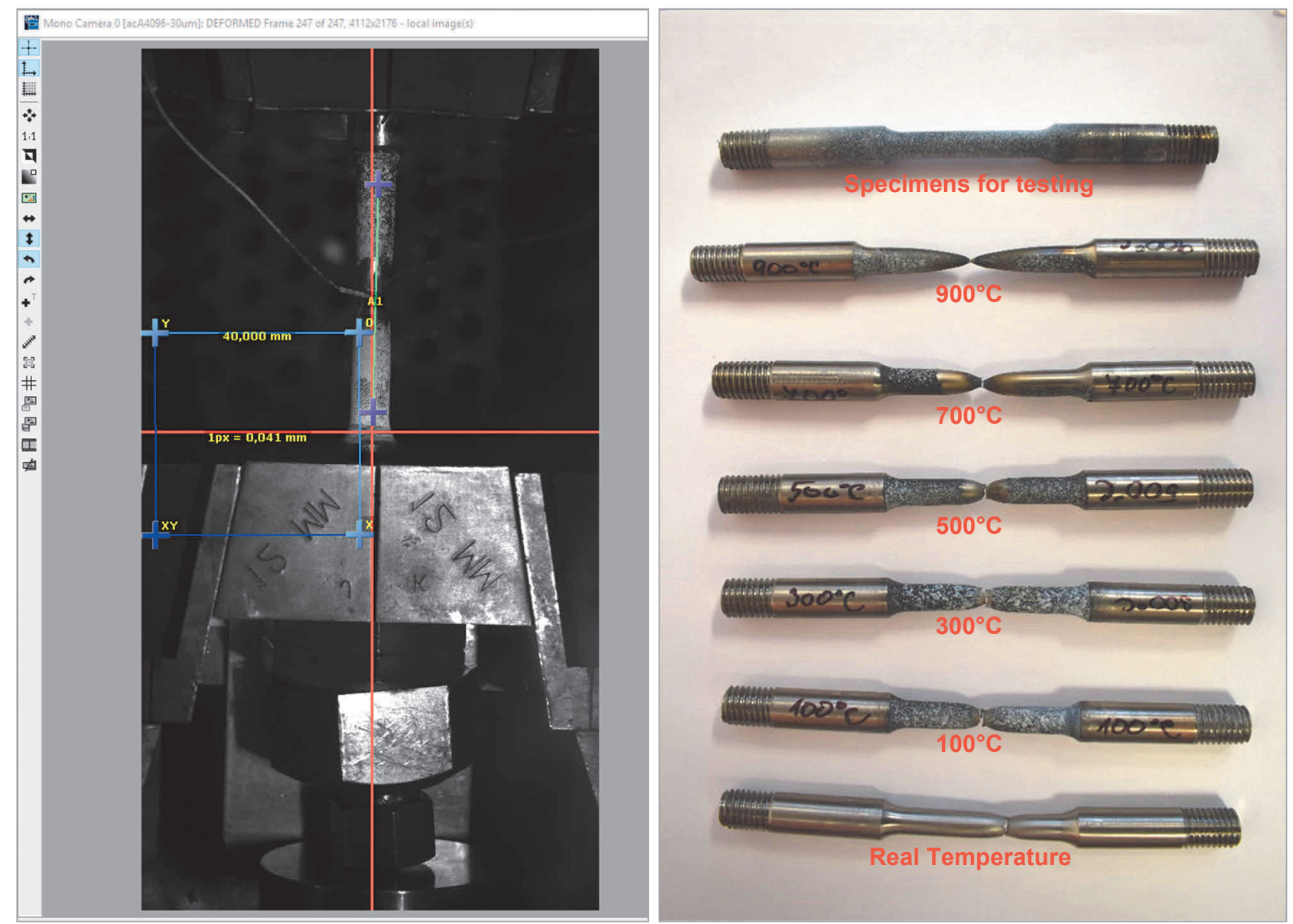

Figure 2 Measurement in the Mercury software (left) and tested specimens after tensile test (right)

Table 1 shows the resulting mechanical properties of the titanium alloy $6 \mathrm{Al}-4 \mathrm{~V}$ with respect to the selected test

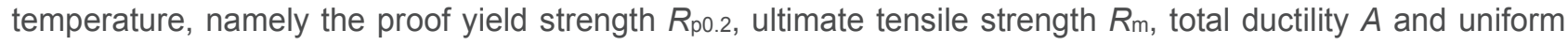
ductility $A_{g}$. These values of monitored mechanical properties always represent the mean values measured from 5 specimens for each temperature.

Table 1 Mechanical properties of titanium alloy $6 \mathrm{Al}-4 \mathrm{~V}$

\begin{tabular}{|c|c|c|c|c|}
\hline $\begin{array}{c}\text { Temperature } \\
\left({ }^{\circ} \mathbf{C}\right)\end{array}$ & $\begin{array}{c}\mathbf{R}_{\mathbf{p} 0,2} \\
(\mathbf{M P a})\end{array}$ & $\begin{array}{c}\mathbf{R}_{\mathbf{m}} \\
(\mathbf{M P a})\end{array}$ & $\begin{array}{c}\mathbf{A}_{\mathbf{g}} \\
(\%)\end{array}$ & $\begin{array}{c}\mathbf{A} \\
(\%)\end{array}$ \\
\hline $\mathbf{R T}$ & 1009.8 & 1105.9 & 3.71 & 13.19 \\
\hline $\mathbf{1 0 0}$ & 905.3 & 1047.8 & 4.96 & 14.00 \\
\hline $\mathbf{3 0 0}$ & 686.8 & 849.6 & 5.63 & 14.94 \\
\hline $\mathbf{5 0 0}$ & 519.9 & 683.5 & 4.19 & 15.78 \\
\hline $\mathbf{7 0 0}$ & 243.1 & 291.3 & 1.82 & 25.59 \\
\hline $\mathbf{9 0 0}$ & 37.3 & 45.5 & 2.49 & 53.30 \\
\hline
\end{tabular}




\section{COMPARISON OF RESULTS}

To determine the mechanical properties of the material, a static tensile test was performed and results of that are illustrated in Figure 3. The figure shows the change in mechanical properties with respect to the temperatures at which the test was carried out. The test results are presented by the most characteristic stressstrain curve from five measured specimens for each temperature.

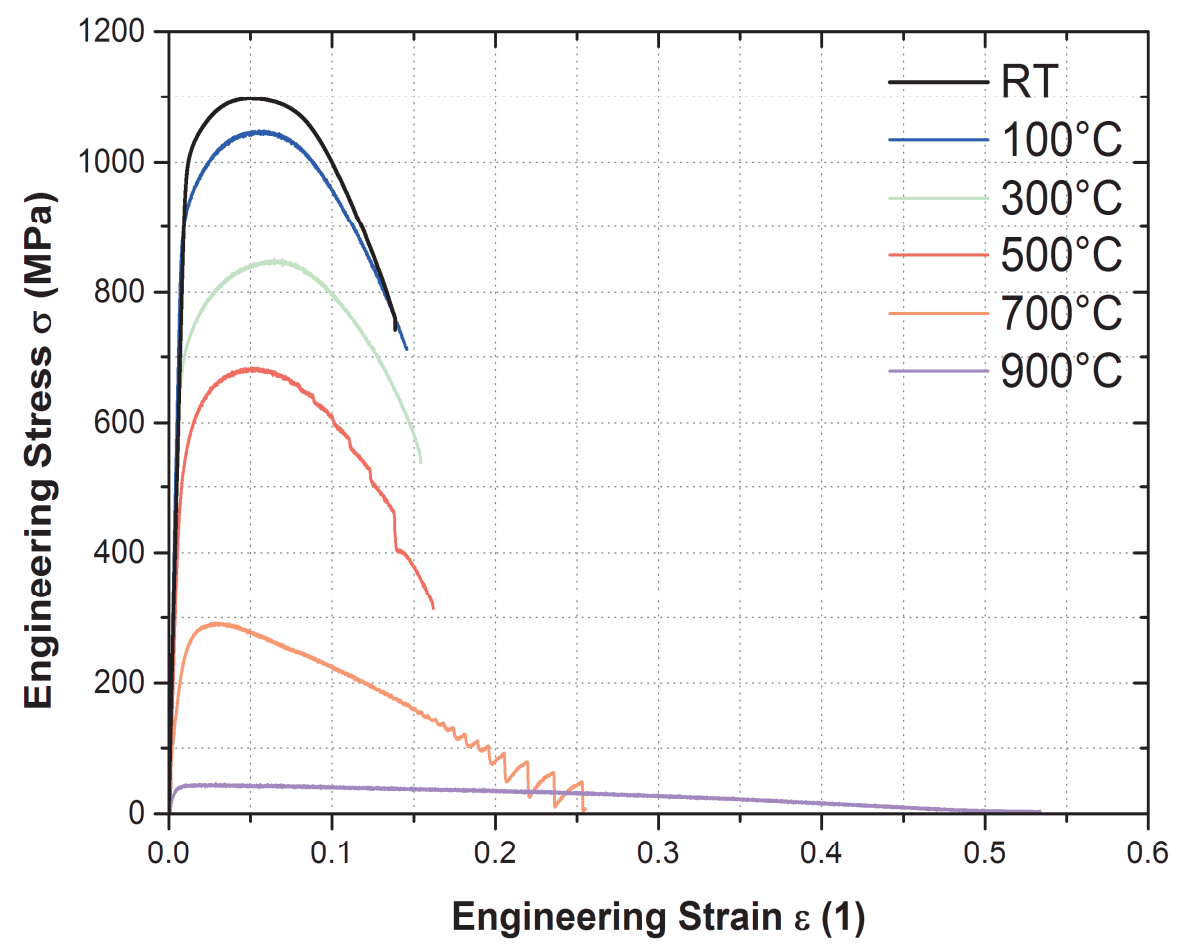

Figure 3 Comparison of results from tensile test at specific temperature levels

The required mechanical properties were obtained by means of the software LabNET. Such basic mechanical properties, which are shown in Table 1, are here illustrated graphically in the form of column graphs. Namely, Figure 4 shows a comparison of the individual tensile ultimate strengths regarding test temperatures (Figure 4 - left) and also the dependence of ductility on the test temperatures (Figure 4 - right).
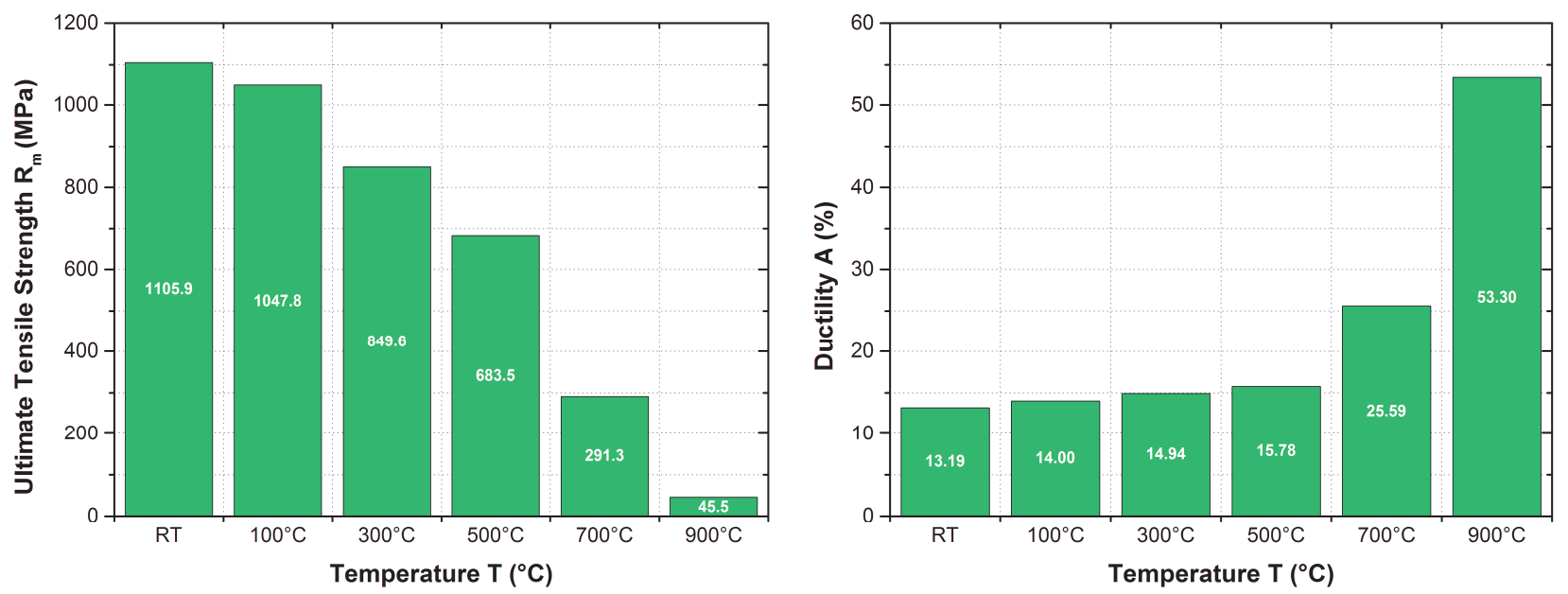

Figure 4 Comparison of chosen mechanical properties at specific temperature levels 


\section{CONCLUSION}

The aim of the paper was to investigate the influence of temperature on the mechanical properties change of titanium alloy Grade 5 (Ti-CP $6 \mathrm{Al}-4 \mathrm{~V}$ ). By means of the static tensile test, the average material stress-strain curves and especially values of basic mechanical properties such as proof yield strength $R_{\mathrm{p} 0,2}$, tensile ultimate strength $R_{\mathrm{m}}$, total ductility $A$ and uniform ductility $A_{g}$ were found. These resulting values are shown and illustrated in Chapters 2 and 3. From the measured values is evident (and in the figures it is illustrated as well) the dependence of the material mechanical properties on the temperature at which the material was tested. In Figure 3, a decrease in strength and an increase in the engineering strain of the tested material can be observed with increasing test temperatures. Figure 4 (left) shows decrease in the tensile ultimate strength due to the increasing temperature level for the static tensile test. Figure 4 (right) shows the increase in material ductility due to increasing temperature. It can be seen from the graphs and illustrations that the temperature has a significant effect on the process of forming the titanium alloy. The greatest changes in the strength values of tested material take place in the temperature range from $300{ }^{\circ} \mathrm{C}$ to $900{ }^{\circ} \mathrm{C}$. In terms of ductility, the highest increase is evident form $700^{\circ} \mathrm{C}$. The biggest changes were achieved first at $700{ }^{\circ} \mathrm{C}$, where the material recrystallization process is in progress and at $900^{\circ} \mathrm{C}$, where occurs the crystal lattice transformation (to be more specific - at $882.5^{\circ} \mathrm{C}$ ).

The measured and experimentally determined values indicate that titanium alloys appear to be relatively suitable and usable for the forming process and subsequent application in the field of mechanical engineering. However, the particular method of processing this material with regard to the technological, process and temperature conditions during its processing should be taken into account.

\section{ACKNOWLEDGEMENTS}

This publication was written at the Technical University of Liberec as part of the project "SGS 21286" with the support of the Specific University Research Grant, as provided by the Ministry of Education, Youth and Sports of the Czech Republic in the year 2019.

\section{REFERENCES}

[1] POLMEAR, I. Ligth Alloy - From traditional Alloys to Nanocrystals. 4th ed. Oxford: Butterworth-Heinemann, 2006. p. 421. ISBN 0-7506-6371-5.

[2] ASTARITA, A., PRISCO, U. Tensile Properties of Hot Stretch Formed Ti-6Al-4V Alloy Component for Aerospace Applications. Manufacturing Technology. 2017, vol. 17, pp. 141-147.

[3] MACHEK, Václav a Jaromír SODOMKA. Speciální kovové materiály. Nauka o materiálu 3. část: Prague: České vysoké učení technické, 2008, p. 118. ISBN 978-800-1042-120.

[4] ASM HANDBOOK. Volume 8 - Mechanical Testing and Evaluation. 10th ed. Materials Park: ASM International, 2000. p. 998. ISBN 0-87170-389-0.

[5] HOSFORD, W.F., CADDEL, R. Metal Forming (Mechanics and Metallurgy). 3rd ed. New York: Cambridge University Press, 2007. 312. ISBN 978-0-521-88151-0. 